\title{
Suspended sediment dynamics by event typology and its siltation effects in a semi-arid snowmelt-driven basin
}

\author{
Agustín Millares ${ }^{1, *}$, Antonio Moñino ${ }^{1}$, Sergio Arjona ${ }^{2}$, and Asunción Baquerizo ${ }^{1}$ \\ ${ }^{1}$ Group of Environmental Fluid Dynamics, Andalusian Institute for Earth System Research (IISTA)- \\ University of Granada, Spain \\ ${ }^{2}$ Andalusian Regional Government, Spain
}

\begin{abstract}
Soil loss and transport processes are key issues to understand erosive and sedimentary dynamics in semi-arid environments. The aim of this work was to characterize the erosive patterns of different types of events and to analyse their effect downstream in a mountainous semi-arid watershed. With that purpose, different events have been typified according to atmospheric and hydrological descriptors from information of 1) historical meteorological data, 2) results of simulations from physicallybased and distributed hydrological modeling, which includes the snowmelt dynamics, and 3) available MODIS satellite images. For each event, water samples were taken by an automatic measuring device and analysed to determine the suspended sediment loads. The results allowed to identify three types of events. Among them, the maximum values of the measured suspended solids during rainfall-dominated events, with little snow influence, were an order of magnitude higher than the snowfall-dominated events, with values of $25000 \mathrm{mg} / \mathrm{l}$ versus $2500 \mathrm{mg} / \mathrm{l}$ respectively. The response of intermediate events, despite of low flow, showed a significant gradient. The results highlight the great dynamic variability of the sediment yield along the basin and the importance of the snow in the lamination of the erosive processes and their consequences on reservoir siltation.
\end{abstract}

\section{Introduction}

The dynamics of suspended sediment transport is key to understanding the erosive and sedimentary processes of watersheds. Its relationship with forcing agents along hillslopes and rivers allows us to analyze sediment production, changes in water quality, erosive seasonality [1,2], and reservoir siltation processes [3].

In mountainous catchments, the role of snow and its subsequent melting, have a remarkable influence on erosion and transport as suspended loads. Among other contributions, the low temperature and humidity under these conditions produce freezing and melting cycles that reduce soil stability. Unlike precipitation events, snowmelt events

\footnotetext{
*Corresponding author: mivalag@ugr.es
} 
last longer, with daily and seasonal periods [4, 5], with a greater interaction within the edaphic profile by infiltration, sub-surface flow and wash load processes. The relationship between snowmelt and erosion will depend, to a great extent, on factors such as the soil profile depth, its texture and content of organic matter.

In mountainous semi-arid environments (e.g. Andes, Himalayas, Atlas, ...), the dynamics of daily and seasonal snowmelt pulses are very intense [6] and produce episodes of moderate floods with repercussions on bedload transport processes at the rivers $[7,8]$, and sub-surface soil wash at hillslopes [9]. The irregular spatial and temporal distribution of the governing agents, frequent on these environments, is even more complex if we consider the pronounced gradients and the influence of mountainous areas. The combination of different climatic, topographic, land-uses or edaphic factors greatly affects atmospheric and hydrological processes with different responses in erosion and sediment yield along the contributing watersheds. The rainfall/snowfall fraction has also a significant impact on the lamination of the erosive processes in these areas. However, the relationship between this set of processes and their associated impact on erosive responses has not been deeply analyzed in most cases. This is of specially relevant in semi-arid mountainous environments from the water management and soil conservation point of view and in a global change context.

The aim of this work is to characterize the erosive dynamics of suspended sediment for different types of events and to analyze their effect downstream in a mountainous semi-arid environment. With that purpose, different events were measured and classified according to the influence of the snow dynamics, the spatial distribution of precipitation and runoff. For each of them, its erosion capacity was estimated from suspended loads and its impact in terms of reservoir siltation was assessed.

\section{Study area and measurements}

The area of study is the Guadalfeo watershed (SE of Spain), located in the southern face of Sierra Nevada mountains (3500 m. asl), a semi-arid mountainous environment highly influenced by the snow dynamics (Fig. 1). The Guadalfeo river, of quasi-ephemeral nature, presents important flow variations, with average flows around $4,5 \mathrm{~m}^{3} / \mathrm{s}$ and peak flows during extreme events that can exceed $500 \mathrm{~m}^{3} / \mathrm{s}$ [10]. Alternating Atlantic and Mediterranean storms produce different types of events with significant accumulation of snow on the summit of Sierra Nevada and cold air pool episodes.

The main contributing sub-catchments belong to the Sierra Nevada Massif, of metamorphic geology, which presents a gentle relief and numerous rocky outcrops. The high degree of fracturing in the aquifer domain allows different baseflow responses [11]. In this area, the snow dynamics highly affects water and sediment fluxes during punctual snowmelt events or annual snowmelt period from May to July. Land uses are conditioned by the protection of the Sierra Nevada National Park, managed by the regional government, with a high percentage of high mountain pastures and forest areas, mainly pine and oak. In the lower area, the terraced crops are combined with grazing practices. The average erosive rate in this zone is between $5-20 \mathrm{t} /$ (ha yr) [12].

On the opposite side of the watershed, La Sierra de la Contraviesa $(1545 \mathrm{~m}$. asl) is geologically formed by a combination of metamorphic rocks (Paleozoic slates and micaschist) and sedimentary rocks (sandstones, gypsum and conglomerates) that generate mainly a siliceous terrain. Almond crops and vineyards on steep slopes at the headwaters predominate in this area, with erosive rates that exceed $200 \mathrm{t} /$ (ha yr) and many erosional processes by gullying $[12,13]$. 


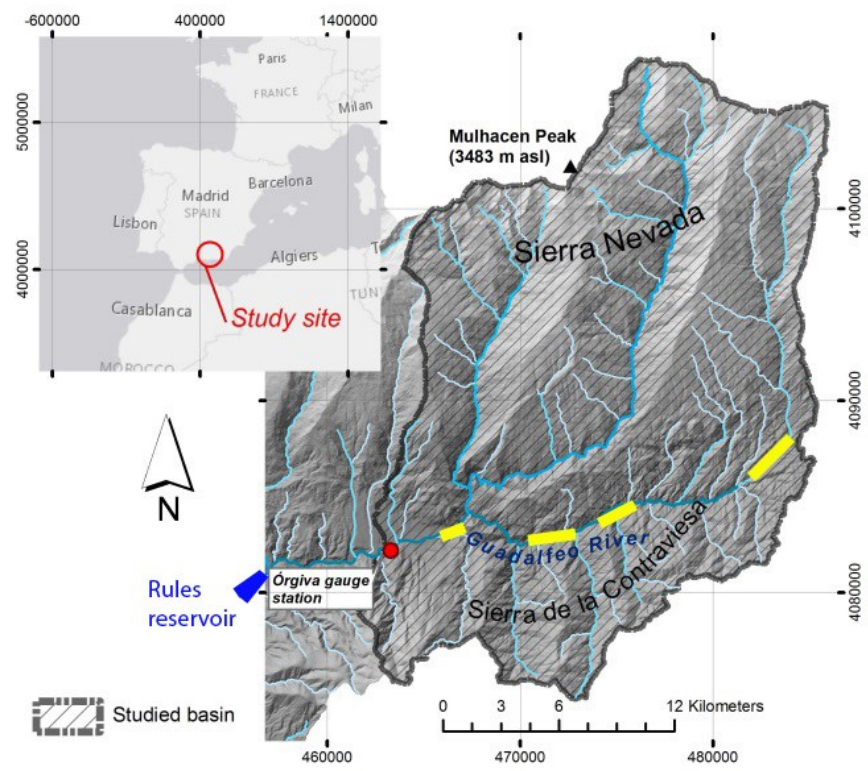

Fig. 1. Location of the study site, basin and sub-basins, sampling area (red circles) and Rules reservoir (blue circle).

The information of the involved meteorological agents such as precipitation, snowfall, temperature, radiation, humidity and wind speed, were obtained by continuous measurement from 4 weather stations located at different altitudes to capture the topographically induced gradients. This information and data previously recorded in other stations were used to extrapolate their spatial variability and to characterize them.

The events measured were finally studied in terms of different hydrological descriptors obtained from information of 1) recorded and historical meteorological data, 2) results of simulations obtained with a physically-based and distributed hydrological modeling, which includes the snowmelt dynamics, and 3) available MODIS satellite images. More precisely, he following descriptors were considered:

1. Snow precipitation fraction $P_{S F}$ (dimensionless) defined as the fraction of snowfall relative to the total amount of precipitation during the event, estimated with the expression

$$
P_{S F}=\sum_{i=1}^{N} \frac{P_{i, S}}{P_{i, s}}
$$

where $P_{i}$ it is the rainfall registered during day $i$ rainfall $(\mathrm{mm}), P_{i, s}$ is the snowfall precipitation $(\mathrm{mm})$ in that day and $N$ is the total duration in days of the measured event.

2. The fraction of liquid water entering the system during the event, $F_{L W}$ (dimensionless), defined as

$$
F_{L W}=\sum_{i=1}^{N} \frac{P_{i}-P_{i, s}+S_{i, m}}{P_{i}+S_{i, m}}
$$

where $S_{i, m}$ is the amount of snowmelt during the event $(\mathrm{mm})$. This variable was estimated from the physically-based and distributed hydrological model WiMMed [14], calibrated and validated in the study area, which includes an energy balance model to simulate the hourly cycles of snowmelt.

3. Snow retention fraction, $R_{S F}$, (dimensionless), defined as

$$
R_{S F}=\sum_{i=1}^{N} \frac{P_{i, S}}{S_{i, m}}
$$

4. Snow cover variation, $\Delta S_{S C}$, (dimensionless), defined as

$$
\Delta S_{s c}=S_{S c_{-} t 2}-S_{S c_{-} t 1}
$$


where $S_{S c_{-} t 1}$ and $S_{S c_{-} t 2}$ are the relative surfaces regarding the total watershed area at the initial and final time of the events respectively. This indicator was estimated from the available MODIS satellite images, with high temporal resolution ( 1 day) despite relatively low spatial resolution $(500 \mathrm{~m})$.

5. The runoff coefficient, $C$ (dimensionless), defined as

$$
C=\frac{86.4}{A} \sum_{i=1}^{N} \frac{Q}{P_{i}-P_{i, S}+S_{i, m}}
$$

where $Q_{i}$ is the measured flow at the outlet of the basin $\left(\mathrm{m}^{3} / \mathrm{s}\right)$ and $A$ is the total area of the watershed $\left(\mathrm{m}^{2}\right)$

6. Index of spatial variability, $S V_{P}$, (dimensionless) that takes into account the differences in spatial distribution between storms in Sierra Nevada and the Sierra de la Contraviesa

$$
S V_{P}=\frac{P_{s t 4}}{\bar{P}}
$$

where $P_{s t 4}$ is the average precipitation registered at station of Sierra de la Contraviesa (mm) and $\bar{P}$ is the average precipitation recorded in all weather stations (mm).

Several samples suspended sediment were taken on different field campaigns along the river, and with an automatic device at the Rules reservoir' entrance. Table 1 shows the location, sampling method, number of events and samples collected during campaigns developed over the years 2004, 2005, 2015 and 2016. The samples obtained were first treated to eliminate organic matter and then analyzed in accordance with the TSS 160.2 protocol [15], to estimate the concentration of suspended sediment.

Table 1. Measuring and sampling techniques for suspended sediment assessment.

\begin{tabular}{|l|c|c|}
\hline Sampler location & Along the river & Reservoir entrance \\
\hline Sampler method & Bottle & Isco-6712 \\
\hline Number of events & 8 & 14 \\
\hline Number of samples & 51 & 63 \\
\hline
\end{tabular}

Simultaneously, the flow was recorded accurately at the gauge station located close to entrance of the reservoir.

\section{Results}

The results of suspended sediment measurements, and their relationship with the forcing agents characterized by the above mentioned descriptors, showed different erosive dynamics in the study area.

Table 2 shows the values obtained for the 6 descriptors. As observed, significant differences allow for typifying events mainly attending to three aspects 1) the influence of snow melted after the event or by the amount of precipitation in the form of snow, 2) the spatial distribution of the precipitation and 3) the capacity of the event to generate direct runoff. Accordingly, three type of events were identified:

Type I; snowfall-dominated: Described events measured during February to March with an important amount of snowfall fraction which is retained at the mountainous area of Sierra Nevada. The amount of precipitation during them is also relevant, in the range of $80<P<130 \mathrm{~mm}$ and generally presents a homogeneous spatial distribution over the watershed, with relatively higher values in the summits.

Type II; intermediate snowfall-dominated: These events have some common aspects with those of Type I although with considerable minor amount of precipitation $10<\mathrm{P}<40$ $\mathrm{mm}$. They present a smaller proportion of snowfall and more liquid contribution, with higher runoff coefficient and snow melting ratio than the previous type. 
Type III; rainfall-dominated: They are related to the atmospheric events coming from the Mediterranean Sea and, therefore, with a more heterogeneous rainfall distribution mainly concentrated in the Sierra de la Contraviesa. They have a moderate precipitation magnitude $15<\mathrm{P}<33 \mathrm{~mm}$, scarce snow influence and a significant contribution of liquid water and runoff to the system.

Table 2. Hydrological descriptors values by typified events

\begin{tabular}{|c|c|c|c|}
\hline Hydrological index & Type 1 & Type 2 & Type 3 \\
\hline$P_{S F}$ & $>0.4$ & $\leq 0.4$ & $\leq 0.4$ \\
\hline$F_{L W}$ & $\leq 0.75$ & $>0.65$ & $>0.85$ \\
\hline$R_{S F}$ & $\leq 0.45$ & $>0.45$ & $>0.45$ \\
\hline$\Delta S_{S C}$ & $<0.2$ & $<0.2$ & $<0.01$ \\
\hline$C$ & $<0.3$ & $<0.2$ & $>0.3$ \\
\hline$S V_{P}$ & $<1$ & $<1$ & $>1$ \\
\hline
\end{tabular}

Figure 2 shows nine selected sedimentograph of different typologies for the studied area. As can be observed, events of type I ( 1 and 2) maintain a high residual value, between 500 and $600 \mathrm{mg} / \mathrm{l}$ at the end of the event. In Type II events, 3, 4, 5, 6 and 8 in Figure 2, this residual effect is not clear and it is only visible for event 5 , with approximately $500 \mathrm{mg} / \mathrm{l}$ in post-event situation.
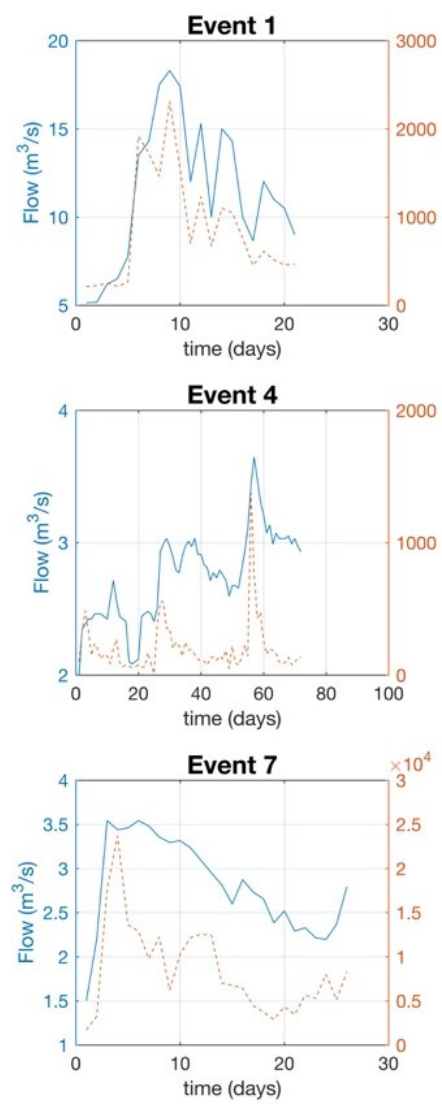

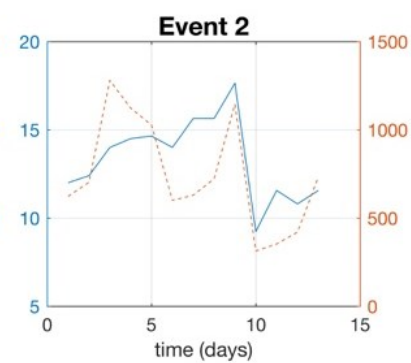

Event 5
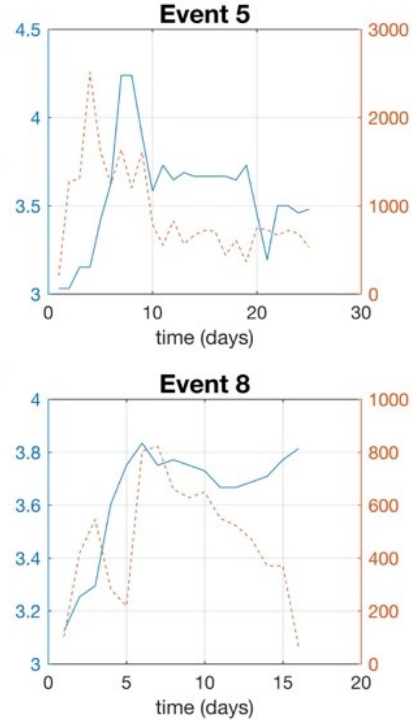

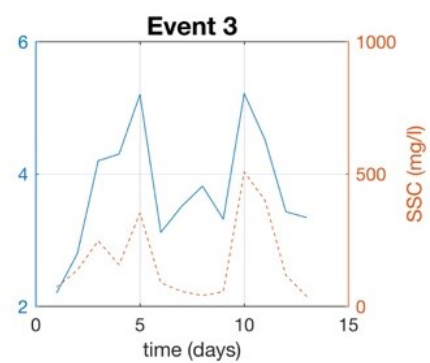

Event 6
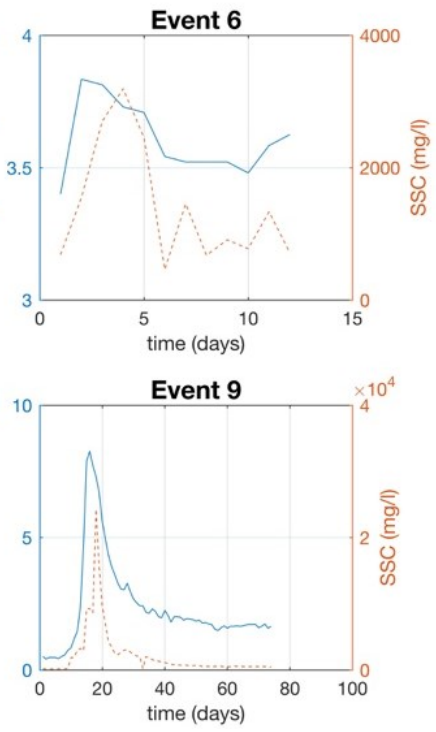

Fig. 2. Hydrograph and sedimentograph for 9 of the measured events at the reservoir's entrance. 
The events of type III, 7 and 9 in Figure 2, show an order of magnitude higher than the previous events with maximum values higher than $20,000 \mathrm{mg} / \mathrm{l}$, relatively high in comparison to the maximum value of the flow registered in the corresponding gauging stations, 3,5 y $8 \mathrm{~m}^{3} / \mathrm{s}$ respectively.

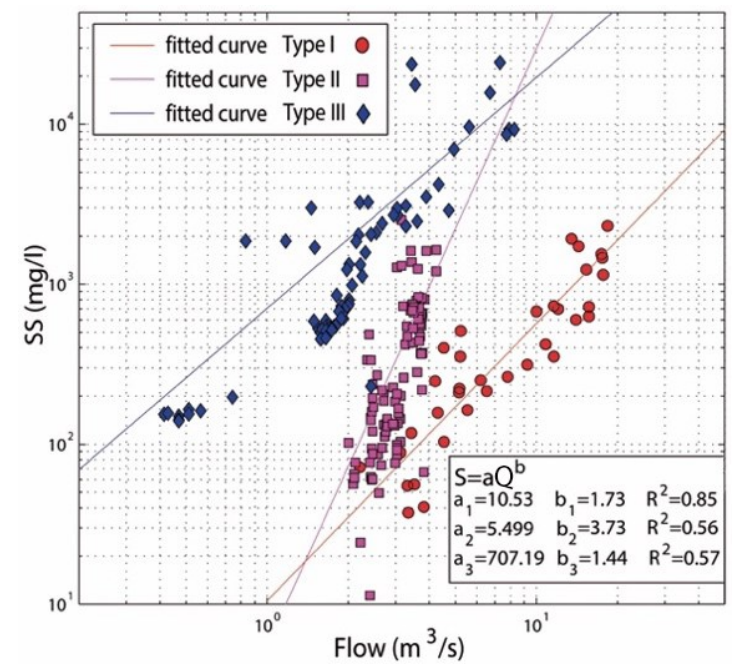

Fig. 3. Rating curves by typified events. Fitted curves, parameters and determination coefficient are shown.

Figure 3 shows the obtained rating curves. Differences in the erosive response according to the type of the event considered can be clearly observed. The different types of events were adjusted based on the relationship $S=a Q^{b}$, where $S$ is the suspended sediment concentration $(\mathrm{mg} / \mathrm{l}), Q$ is the measured flow $\left(\mathrm{m}^{3} / \mathrm{s}\right)$ and $a$ y $b$ are fitted parameters. The results show goods adjustments with high determination coefficients especially for events of Type I.

A similar relationship can be also observed in the response between type I and type III events, although an order of magnitude higher. The response of type II events, in a low range of measured flows, shows however a significant gradient, $b=3.73$, for the erosive response of the watershed.

Figure 4 shows the existing relationship between the sediment yield estimated for each event and the runoff coefficient (a) or the fraction of liquid water during the event (b). As can be observed, there is a very clear linear relationship between runoff and sediment yield, which also reflects the ability of the snow to attenuate the erosive processes.

During the sedimentation processes measured at the Rules reservoir, the accumulated volume at the bottomset was related to suspended sediment loads and to hillslope areas [3]. From the obtained results, the event that caused such a siltation was of Type I, with important rainfall and snowfall contributions, although with a notably higher magnitude than have been measured in this work. Such an event, caused a decrease of nearly $4 \%$ of the total available volume of water of the reservoir.

Furthermore, if we consider the historical events at the watershed, the event of October1973, with an associated return period of 500 years, low snowfall contributions and centered at the Sierra de la Contraviesa, we can classify it as Type III from the results of this research. We could infer the huge importance of the erosive processes and lost of services (water volume, soil loss, ...) for such events at the study area. 

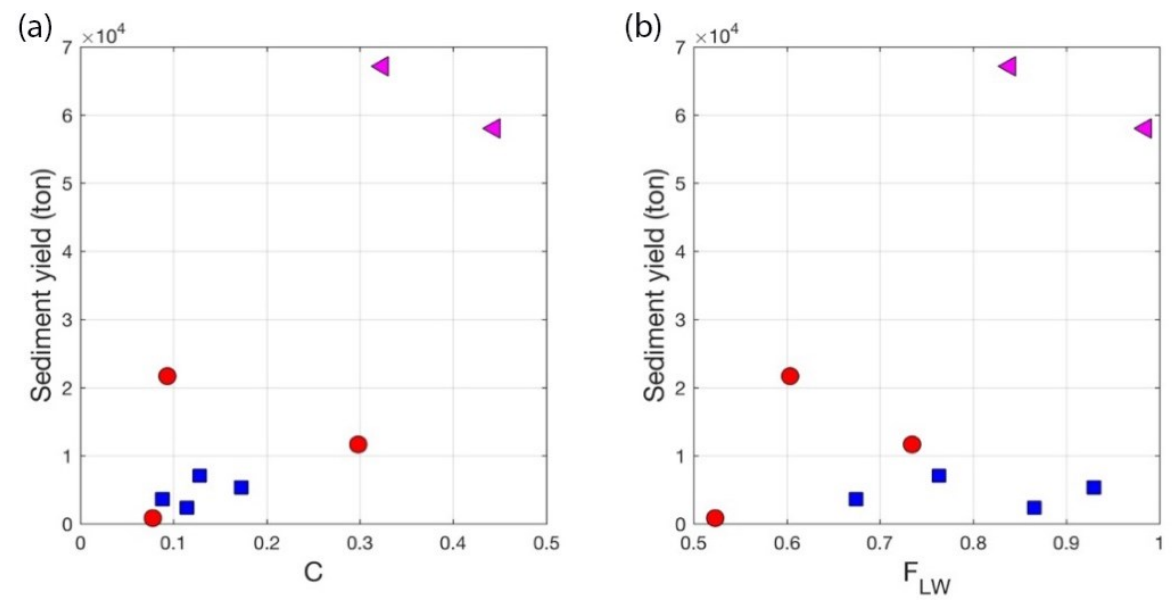

Fig. 4. Relationship between sediment yield and runoff coefficient (a) and fraction of liquid available water (b) by typified events (Type I= red circles, Type II= blue squares, Type III= magenta triangles).

\section{Conclusions}

The results allowed to identify three types of erosive response events according to the climatic and hydrological characteristics of the forcing agents. The maximum values of the measured suspended solids during events with little snow influence (Type III), were an order of magnitude higher than events with higher snowfall (Type I), with values of 25000 $\mathrm{mg} / \mathrm{l}$ versus $2500 \mathrm{mg} / \mathrm{l}$ respectively. These results show the high character of snow for attenuation erosive processes of precipitation events. The sedimentograph analyzed also highlight these differences in transport dynamics between the characterized events, with residual values of suspended sediment concentration higher during the post-event when its nature was markedly snowy.

Although the sedimentation processes associated with suspended sediment at the Rules reservoir, distributed along the bottom-set, have been previously linked with Type I events, the results of this work suggest caution on siltation prediction and useful life. The differences of sediment dynamic found from this research could be particularly relevant for erosive processes in a climate change scenario that will probably increase the frequency and intensity of Type III events.

The first author of this research would like to acknowledge the support of the H2020 European project "ECOPOTENTIAL: improving future ecosystem benefits through earth observations" (Grant Agreement 641762). The authors would like to acknowledge the support of the AQUACLEW project (Advancing QUAlity of CLimate services for European Water) co-funding from the European Commission (Grant Agreement 690462).

\section{References}

1. J. Farguell, M. Sala, in: Soil Erosion and Sediment Redistribution in River Catchments. CABI, 85-107 (2006)

2. A. Rovira, R.J. Batalla, Geomorphology 79, 58-71 (2006)

3. A. Millares, M.J. Polo, A. Moñino, J. Herrero, M.A. Losada, in: Reservoir Sedimentation-Special Session on Reservoir Sedimentation of the 7th International Conference on Fluvial Hydraulics (River Flow 2014), 91-98 (2014) 
4. G. Ollesch, I. Kistner, R. Meissner, K.E., Lindenschmidt. Catena 68, 161-176 (2006)

5. A. Tanasienko, O. Yakutina, A. Chumbaev, Catena 87, 45-51 (2011)

6. J. Herrero, M.J. Polo, A. Moñino, M.A. Losada, Journal of Hydrology 371, 98-107 (2009)

7. A. Millares, M.J. Polo, Moñino, A., Herrero, J., Losada, M., Geomorphology 206, 330-342 (2014)

8. A. Monino, A. Millares, J. Herrero, M.J. Polo, M.A. Losada, in: EGU General Assembly Conference Abstracts, 10756 (2011)

9. A. Millares, R. Torres, C. Aguilar, M.J. Polo, in: EGU General Assembly Conference Abstracts, 16273 (2014)

10. J. Capel, Cuadernos de Geografía, 4, 149-166 (1974)

11. A. Millares, M.J. Polo, M.A. Losada, Hydrology and Earth System Sciences 13, 12611271 (2009)

12. Dirección General de Medio Natural y Política Forestal. Inventario Nacional de Erosión de Suelos. Comunidad Autónoma de Andalucía. Granada. (Ministerio de Medio Ambiente Rural y Marino, Madrid, 2007)

13. A. Millares, Z. Gulliver, M.J. Polo, Geomorphology 153-154, 115-126 (2012)

14. J. Herrero, C. Aguilar, A. Millares, M. Egüen, M. Carpintero, M.J. Polo, M.A. Losada, WiMMed. User Manual v1.1. (University of Granada, Granada, 2010)

15. U.S. Environmental Protection Agency, Method 160.2: Total Suspended Solids (TSS)(Gravimetric, Dried at 103-105) (Revised Ed. USEPA, Washington, 1999) 